\title{
Dissociating recollection from familiarity: Electrophysiological evidence that familiarity for faces is associated with a posterior old/new effect.
}

\author{
Graham MacKenzie* and David I Donaldson \\ Psychological Imaging Laboratory, Department of Psychology, University of Stirling, \\ Stirling, FK9 4LA, UK
}

GM is supported by a PhD studentship from the Department of Psychology, University of Stirling. DID is supported by the BBSRC.

\footnotetext{
*Corresponding author

Department of Psychology

University of Stirling

Stirling FK9 4LA

UK

Email: d.g.mackenzie@stir.ac.uk

Fax: $\quad+44(0) 1786467641$

Tel: $\quad+44(0) 1786466365$
} 


\begin{abstract}
In recognition memory research, a tension exists between dual-process and single-process models of episodic retrieval. Dual-process models propose that 'familiarity' assessment and the 'recollection' of contextual information are independent processes, while singleprocess models claim that one common process supports retrieval. Event-related potentials (ERPs) have been used to show dissociations between the mid frontal and the left parietal ERP old/new effects, which have been associated with familiarity and recollection, respectively. While much ERP evidence favours dual-process theory, Yovel and Paller (2004) used faces as retrieval cues to demonstrate that posterior old/new effects index both familiarity and recollection, a finding consistent with single process models. Here we present evidence supporting Yovel and Paller's claim that a posterior old/new effect indexes familiarity for faces, along with a novel finding that recollection is associated with an anterior old/new effect. Importantly, and in contrast to Yovel and Paller, the old/new effects associated with familiarity and recollection were topographically dissociable, consistent with a dual process view of recognition memory. The neural correlates of familiarity and recollection identified here for faces appear to be different from those typically observed, suggesting that the ERP old/new effects associated with episodic recognition are not the same under all circumstances.
\end{abstract}




\section{Introduction}

Do you ever find someone familiar without recollecting any specific information such as where or when you know them from? This common experience, summed up by the phrase 'I know your face but I can't remember your name', encapsulates the 'dual process' view of episodic memory. According to dual process models, performance on recognition tests can reflect the assessment of stimulus 'familiarity', or 'recollection' of details about a previous episode (Atkinson and Juola, 1974; Mandler, 1980; Tulving, 1985; Yonelinas, 1994). Much evidence for dual process models originates from recognition tests employing lexical stimuli. By contrast, here we investigate the common experience described above, asking if recollection and familiarity can also be identified in face recognition tests. We describe an experiment using event-related potentials (ERPs) that provides strong evidence for a dual process view of episodic retrieval, while challenging dominant ideas about the neural correlates of familiarity and recollection.

Various dual process models exist, each making competing predictions about the exact nature of familiarity and recollection (for a review, see Yonelinas, 2002). Despite their differences, these models converge on the view that familiarity is relatively automatic, occurring early in the processing stream, while recollection is more controlled and occurs later. To be clear, we view familiarity as supporting the conscious experience of having encountered a stimulus before, without the retrieval of contextual information about the prior episode, whereas recollection allows additional contextual information to be reported. Despite the relative parsimony of single-process models (e.g. Donaldson, 1996), which argue that familiarity is simply sub-threshold recollection, a body of evidence 
indicates that two dissociable processes underpin episodic recognition. Here we briefly review ERP evidence, which has identified neural correlates of familiarity and recollection.

When stimulus-locked ERP waveforms for correctly recognised old items ('hits') are compared to correctly recognised new items ('correct rejections'), the old waveform is more positive going at a number of different scalp locations and at a range of different latencies. This 'ERP old/new effect' reflects the summed activity of multiple subcomponents, providing evidence for the contribution of dissociable cognitive processes to recognition performance (e.g., see Donaldson et al., 2002). Most relevant here, a mid frontal old/new effect (300 - 500ms) has been linked with familiarity (Rugg et al., 1998; Curran, 2000; Curran and Cleary, 2003; Mecklinger, 2000 - although see Tsivilis et al., 2001 for an alternative interpretation) and a left parietal old/new effect (500 - 700ms), varies in a manner consistent with recollection (Wilding and Rugg, 1996; Donaldson and Rugg, 1998; Curran, 2000; see Allan et al., 1998, for a review). Importantly, evidence suggests that the two ERP effects are dissociable on both topographic (e.g. see Rugg et al., 1998) and functional grounds (e.g., see Rhodes and Donaldson, in press; Greve et al., in press) providing strong evidence for dual process accounts.

The majority of the ERP evidence supporting dual process models comes from paradigms using lexical stimuli. Recently, Yovel and Paller (2004) argued that the use of lexical stimuli introduces a confound because the stimuli possess a pre-existing level of 
familiarity; instead, they attempted to isolate familiarity-based responding using novel faces as stimuli. Faces of unknown individuals were paired with spoken occupations at study; old and new faces were intermixed and presented alone in the test phase.

Participants indicated what type of information was retrieved at test. For all items endorsed as being 'old', a three-way response choice was made: occupation, other specifics, and no specifics. Importantly, Yovel and Paller argued that occupation and other specifics responses required recollection, while a no specifics response was made in the absence of recollection. The no specifics response was assumed to index familiarity for faces that are uncontaminated with pre-experimental exposure.

Yovel and Paller found that the no specifics old/new effect exhibited a parietal distribution from $500-700 \mathrm{~ms}$ : there was no evidence of the mid frontal effect typically associated with familiarity. The absence of a mid frontal effect was interpreted as resulting from the use of non-nameable stimuli, suggesting that its presence in studies using lexical stimuli reflects 'conceptual priming' rather than familiarity. Thus, Yovel and Paller argued that the parietally distributed old/new effect seen for faces represents the neural correlate of familiarity. The occupation old/new effect also exhibited a parietal distribution during the same time window, albeit exhibiting an earlier onset, longer duration and wider spread across the scalp. Critically, the distributions of the no specifics and occupation old/new effects were statistically equivalent, leading to the conclusion that common neural generators support both familiarity and recollection. 
Yovel and Paller's finding poses two problems for dual process accounts of recognition memory. First, familiarity and recollection are assumed to be qualitatively distinct, and should therefore exhibit topographically dissociable neural correlates. It is worth noting that the occupation effect did exhibit a more anterior maximum than that of the no specifics effect; it remains possible that a topographic difference was not found due to the relatively low density of scalp electrodes. Second, dual process theories posit that familiarity occurs before recollection. According to Yovel and Paller's data, however, the neural correlate of recollection onsets before that of familiarity. Taken together, the timing and distribution of these effects are difficult to reconcile with dual process theory.

Dual process theory predicts that familiarity and recollection support recognition of episodes from the past, and the models are agnostic as to the nature of the encoded information. Schloerscheidt and Rugg (2004) have shown that the mid frontal effect is elicited by visually presented test words that were encoded as auditory samples, and therefore that the old/new effect is not modality-specific; these data are consistent with dual process models. Given that the mid frontal effect has also been reported in studies using words (Rugg et al., 1998), pictures (Curran and Cleary, 2003), object forms (Mecklinger et al., 1998) and faces (Nessler et al., 2005) there is good evidence to suggest that the effect does not show material-specificity either. In this respect, Yovel and Paller's demonstration that familiarity for faces elicits a parietal old/new effect is controversial. 
The present study was conducted to gauge whether familiarity for faces is indexed by a parietal old/new effect. The design of the experiment closely resembled that of Yovel and Paller, but with the following deviations: names were paired with faces at study to operationalize the experience of 'I know your face but I can't remember your name'; memory performance for names required the length of study and test blocks to be half the size used by Yovel and Paller; a dense array of 61 electrodes was used to lend topographic analyses greater sensitivity to detect subtle differences in the distribution of old/new effects between conditions. In addition, the faces used were masked of hair, ears and background in a bid to force participants to use facial information alone to support recognition. If the mid frontal old/new effect provides a generic index of familiarity then it should be elicited by face stimuli; however, if this is not the case, following Yovel and Paller, familiarity should elicit a parietal old/new effect. Either way, from a dual process perspective, dissociable neural correlates of recollection and familiarity would be expected.

\section{Methods}

Twenty-four (13 female) right-handed, native English speakers with a mean age of 23

(range: $18-35$ ) gave informed consent and participated in the study. Participants reported having normal or corrected-to-normal vision, and were paid $£ 5$ per hour. Nine participants failed to contribute enough trials to all 4 conditions; data from the remaining 15 participants are presented here. 
Faces were shown on a monitor and names were presented through speakers located on either side of the monitor; stimuli were presented and behavioural data were recorded with E-Prime (Psychology Software Tools; http://www.pstnet.com). Participants sat on a chair approximately one meter away from the monitor, with a button box on their lap. All faces were of young Caucasian individuals who did not wear any jewellery, glasses or facial hair. Facial images were masked to remove background, hair and ears, before being resized and positioned in the centre of the display. To eliminate gross differences in luminance between individual stimuli, faces were morphed $25 \%$ towards average colour using Psychomorph software (Tiddeman et al., 2001). In addition, half of the faces were morphed $50 \%$ towards average face shape, counterbalanced across participants. All data reported here are collapsed across morphing conditions: despite the intention to examine the effects of morphing, in practice there were insufficient trial numbers to examine ERPs for unmorphed and morphed conditions separately. Faces were presented against a black background, and subtended a maximum horizontal visual angle of $2^{\circ}$ and a maximum vertical visual angle of $5^{\circ}$. Male names were spoken in a male voice and female names were spoken in a female voice (see Supplementary Material for details of the names used). Auditory samples were edited to ensure that face and word onset coincided.

Data were acquired during 18 study-test blocks. Each block contained 12 unique facename pairings presented at study, and was followed by the same 12 faces intermixed with 6 new faces at test. Each block contained an equal number of male and female faces. The test status of the faces was rotated across participants such that each face had an equal chance of being new at test. Within each block there was random selection of faces to 
counter against order of presentation effects. The study and test phase procedures are illustrated in Figure 1.

\section{***INSERT FIGURE 1 ABOUT HERE***}

In the study phase, each trial began with a grey fixation cross $(+)$ presented in the centre of the screen against a black background for $1000 \mathrm{~ms}$. The fixation cross was followed immediately by a face presentation which lasted for $2000 \mathrm{~ms}$. At face onset, a name was presented auditorily. After face offset, participants made a binary judgment as to whether the face fit the name. Participants responded with one of two buttons, and their response terminated the trial. Participants were told that the judgment was arbitrary, and that the task was designed to help them remember face - name associations for the test phase.

In the test phase, each trial began with a grey fixation cross presented against a black background for $1500 \mathrm{~ms}$. The fixation cross was replaced by a face presentation that lasted for 500ms. After face offset, a black screen was displayed for 2000ms, while participants indicated whether they thought the face was 'old' or 'new' by pressing one of two buttons. If a 'new' response was made, the trial terminated. If an 'old' response was made, the black screen was followed by a prompt indicating three response options: name, other specifics and no specifics. If a no specifics or an other specifics response was made, this terminated the trial. Participants were asked to respond no specifics if recognition was devoid of contextual retrieval and to respond other specifics if they recollected information from the study episode but could not retrieve the name that was 
paired with the face. Participants were asked to respond name if they could recall the name that was paired with the face at study, and were required to report the name. The experimenter pressed a key to terminate the trial having recorded the reported name.

The response options allowed trials to be sorted into recollection and familiarity bins for averaging EEG into ERPs. Recollection was inferred on trials where participants made either a name or an other specifics response to a studied face. Following Yovel and Paller, where participants failed to supply the correct name for any face then the trial was recoded as other specifics. Both name and other specifics responses require the participant to reinstate aspects of the study episode and therefore require recollection. Familiarity was inferred on trials where participants made a no specifics response to a studied face. Participants are assumed to make this response when recognition of a face fails to reinstate any of the context in which the face was previously encountered, providing an analogue of recognition supported by familiarity.

During testing, EEG was recorded from 61 silver/silver chloride electrodes embedded in an elasticised Quick-Cap (Neuromedical Supplies: http://www.neuro.com). Electrodes used were: FP1, FP2, AF3, AF4, AF7, AF8, FZ, F1, F2, F3, F4, F5, F6, F7, F8, FCZ, FC1, FC2, FC3, FC4, FC5, FC6, FT7, FT8, CZ, C1, C2, C3, C4, C5, C6, T7, T8, CPZ, CP1, CP2, CP3, CP4, CP5, CP6, TP7, TP8, PZ, P1, P2, P3, P4, P5, P6, P7, P8, POZ, PO3, PO4, PO5, PO6, PO7, PO8, OZ, O1, O2. All channels were referenced to an electrode placed on the right mastoid process and an additional electrode was placed on the left mastoid. Electrode positions were based on the International 10-20 system 
(Jasper, 1958). Electro-oculogram (EOG) electrodes were placed above and below the left eye, and on the outer canthi. Data were recorded using Scan 4.2 software (http://www.neuro.com). Impedances were maintained below $5 \mathrm{k} \Omega$. The data were band pass filtered between 40 and $0.01 \mathrm{~Hz}$ and digitised at a rate of $125 \mathrm{~Hz}(8 \mathrm{~ms} /$ point). Data were re-referenced off-line to an average mastoid reference. EEG was segmented into $1008 \mathrm{~ms}$ epochs, starting $104 \mathrm{~ms}$ before stimulus onset. Ocular artifacts were removed using a regression procedure, and trials were excluded from the averages if EEG saturated, where drift exceeded $\pm 75 \mu \mathrm{V}$ (measured by the difference between the first and last data points in the epoch) or where activity anywhere in the epoch exceeded $\pm 100 \mu \mathrm{V}$. Waveforms were smoothed over a 5-point kernel. To ensure a good signal-to-noise ratio, a minimum of 16 artefact-free trials per condition was set as a criterion before an individual participant's data were included in grand-average ERPs.

Grand-average ERPs were formed for 4 conditions: name, other specifics, no specifics and correct rejection. The average number of trials in these conditions was $32,46,38$ and 69 , respectively. The old/new effects were first characterized separately for the name, other specifics and no specifics conditions, and then comparisons were made between the conditions. ANOVA was performed with the factors of old/new (name/correct rejection; other specifics/correct rejection; no specifics/correct rejection), location (frontal/frontocentral/central/centro-parietal/parietal), hemisphere (left/right) and site (superior/medial/inferior). The specific electrodes included in the analysis were: F1/3/5/2/4/6, FC1/3/5/2/4/6, C1/3/5/2/4/6, CP1/3/5/2/4/6 and P1/3/5/2/4/6. Significant interactions involving the old/new factor were followed up by subsidiary ANOVA carried 
out separately for each location (including factors of hemisphere and site) to identify the locus of differences in the effects. The Greenhouse-Geisser correction for breaches of the sphericity assumption was used as appropriate. Finally, data were rescaled according to the Max-Min method (McCarthy and Wood, 1985) so that topographic analyses were not confounded by amplitude differences.

\section{Results}

\section{Behaviour}

Recognition responses averaged $73 \%$ (s.d. $11 \%$ ) correct for old faces, with $20 \%$ (s.d. 10 $\%$ ) false alarms and $79 \%$ (s.d. $10 \%$ ) correct rejections for new faces. Table 1 shows the percentage of hits subsequently assigned to each of the 3 response categories. A one-way repeated-measures ANOVA revealed no significant differences in performance levels across categories. When a name was produced, it was correct $82 \%$ of the time (s.d. $16 \%$ ).

\section{*** INSERT TABLE 1 ABOUT HERE ***}

The mean response time for correct recognition of old faces ('hits') was 1499ms (s.d. $287 \mathrm{~ms}$ ), and the mean response time for correct rejection of new faces was $1397 \mathrm{~ms}$ (s.d. $282 \mathrm{~ms}$ ). Table 1 also shows the mean response times for hits assigned to each category. A one-way repeated-measures ANOVA revealed a significant difference in response times $[\mathrm{F}(2,28)=11.6 ; \mathrm{p}<0.001]$. Bonferroni-corrected subsidiary t-tests revealed that name responses were significantly faster than both other specifics $[\mathrm{t}(14)=2.9 ; \mathrm{p}<0.05]$ and no specifics $[\mathrm{t}(14)=4.2 ; \mathrm{p}=0.001]$ responses. 


\section{Event-related potentials}

Figure 2 shows the grand-average ERP waveforms at midline frontal and parietal electrodes for the 3 hit conditions compared to correct rejection. In each case, the hit waveform diverges from the correct rejection waveform between 300 and $350 \mathrm{~ms}$ poststimulus. For name and other specifics the difference persists for around $400 \mathrm{~ms}$ and appears largest at the frontal electrode. By contrast, for no specifics, the difference persists for around 250ms and appears largest at the parietal electrode. As can be seen in Fig. 2, the old/new effects are largest for the name condition and smallest for the no specifics condition. To analyse the old/new effects, the waveforms were quantified from $300-500 \mathrm{~ms}$ and from $500-700 \mathrm{~ms}^{1}$. The time windows are those typically used to investigate the neural correlates of familiarity and recollection, and facilitate comparison with the results of Yovel and Paller (2004). The topography of the old/new effects is illustrated in Figure 3, which highlights the anterior distribution for name and other specifics, contrasting with a posterior distribution for no specifics.

\section{***INSERT FIGURES 2 AND 3 ABOUT HERE***}

\section{Name old/new effect}

The analysis of data from $300-500 \mathrm{~ms}$ revealed a main effect of old $/$ new $[\mathrm{F}(1,14)=20.3$; $\mathrm{p}<0.001]$, along with interactions between old/new and location $[\mathrm{F}(1.4,20.1)=5.3 ; \mathrm{p}<$ $0.05]$ and between old/new and site $[\mathrm{F}(1.1,15.1)=7.7 ; \mathrm{p}<0.05]$; these interactions reflect bigger old/new effects at anterior locations, and at superior sites. The old/new effect was significant at all 5 locations, and exhibited a superior distribution at anterior sites (see 
Table 2). Examination of the data revealed that the effect was maximal at FCZ $[\mathrm{t}(14)=$ $4.5 ; \mathrm{p}=0.001]$

For the $500-700 \mathrm{~ms}$ time window, the analysis revealed a main effect of old/new $[F(1,14)=35.2 ; \mathrm{p}<0.001]$ and an interaction between old $/$ new and site $[\mathrm{F}(1.1,14.9)=$ 4.6; $\mathrm{p}<0.05]$, reflecting bigger differences at superior sites. In addition, the analyses revealed interactions between old/new, location and hemisphere $[\mathrm{F}(1.5,21.3)=14.1 ; \mathrm{p}<$ $0.001]$, and between old/new, location and site $[\mathrm{F}(3.2,44.7)=5.3 ; \mathrm{p}<0.01]$. The effect was significant at all 5 locations (see Table 3), and at anterior sites it was bigger on the right hemisphere, and superiorly distributed. Examination of the data found that the effect was maximal at F2 [t(14) $=5.3 ; \mathrm{p}<0.001]$

\section{***INSERT TABLES 2 AND 3 ABOUT HERE***}

\section{Other specifics}

Analysis of data from the $300-500 \mathrm{~ms}$ time window revealed a main effect of old/new $[F(1,14)=9.2 ; \mathrm{p}<0.01]$ and interactions between old $/$ new, location and hemisphere $[\mathrm{F}(1.8,24.8)=4.0 ; \mathrm{p}<0.05]$ and between old $/$ new, location and site $[\mathrm{F}(3.5,48.9)=3.2 ; \mathrm{p}$ $<0.05]$. As can be seen in Table 2, the effect was significant at all 5 locations, but no interactions with hemisphere or site were observed. Additional analyses investigating the initial 3-way interactions examined left and right hemispheres separately at each location. This analysis revealed an interaction between old/new and site at the frontal location on the left hemisphere $[\mathrm{F}(1.3,18.2)=5.0 ; \mathrm{p}<0.05]$ reflecting smaller effects at inferior sites 
than superior sites. Examination of the data found that the effect was maximal at FC2 $[\mathrm{t}(14)=3.3 ; \mathrm{p}=0.005]$

For the $500-700 \mathrm{~ms}$ time window, the analysis revealed a main effect of old/new $[F(1,14)=10.4 ; \mathrm{p}<0.01]$ and an interaction between old/new, location and hemisphere $[F(1.5,20.9)=7.8 ; p=0.005]$. As in the $300-500 \mathrm{~ms}$ time window, the effect was significant at all 5 locations (see Table 3) and there were significant interactions with hemisphere and site at the frontal location, reflecting a right greater than left asymmetry, and the fact that the effects were smaller at inferior sites than superior sites over the left hemisphere only. Examination of the data found that the effect was maximal at AF4 $[\mathrm{t}(14)=3.2 ; \mathrm{p}<0.01]$

No specifics

From $300-500 \mathrm{~ms}$, the analysis revealed a main effect of old $/$ new $[\mathrm{F}(1,14)=11.8 ; \mathrm{p}<$ $0.01]$ and an interaction between old/new and site $[\mathrm{F}(2,28)=4.2 ; \mathrm{p}<0.05]$, reflecting a bigger difference at superior sites. The effect was only significant at the 4 most posterior locations (see Table 2), and was superiorly distributed at fronto-central and central sites. Importantly, the effect was not significant over the frontal string of electrodes. Examination of the data revealed that the effect was maximal at $\mathrm{CZ}[\mathrm{t}(14)=3.5 ; \mathrm{p}<$ $0.01]$

The analysis of data from $500-700 \mathrm{~ms}$ revealed interactions between old/new and location $[F(1.4,20.3)=4.8 ; \mathrm{p}<0.05]$ and between old/new, hemisphere and site $[\mathrm{F}(2,28)$ 
$=8.8 ; \mathrm{p}=0.001]$. The old $/$ new effect was only significant at parietal sites (see Table 3 ).

Interactions between old/new, hemisphere and site were significant at frontal and central sites; however, old/new differences were not reliable at any individual electrode. As can be seen in Fig. 3, the interactions reflect the presence of negativity over the left hemisphere. Examination of the data revealed that the positive going old/new effect was maximal at $\mathrm{P} 4[\mathrm{t}(14)=2.6 ; \mathrm{p}<0.05]$.

\section{Comparison across conditions}

The preceding analyses demonstrate the presence of significant old/new effects for each condition. Subtraction waveforms were computed for all three conditions allowing direct comparison of the sizes of the old/new differences across conditions. Data were submitted to ANOVA with factors of condition (name vs. other specifics/name vs. no specifics/other specifics vs. no specifics), location (frontal/fronto-central/central/centroparietal/parietal), hemisphere (left/right) and site (superior/medial/inferior).

$300-500 \mathrm{~ms}$

When name was compared to other specifics, no differences were observed.

When name was compared to no specifics, the analysis revealed a main effect of condition $[F(1,14)=4.6 ; p<0.05]$ and an interaction between condition and location $[F(1.4,20.1)=5.8 ; p<0.05]$. Subsidiary analyses revealed differences in the pattern of effects across anterior and posterior electrodes; significant main effects of condition were present at anterior locations $($ frontal $[\mathrm{F}(1,14)=7.9 ; \mathrm{p}<0.05]$, fronto-central $[\mathrm{F}(1,14)=$ 
$7.6 ; \mathrm{p}<0.05]$, and central $[\mathrm{F}(1,14)=4.6 ; \mathrm{p}=0.05])$ reflecting a larger old $/$ new difference for name than for no specifics. In addition, an interaction between condition and site $[\mathrm{F}(1.2,16.3)=4.7 ; \mathrm{p}<0.05]$ was present at fronto-central sites, reflecting larger differences over superior sites. Importantly, whilst name was larger than no specifics over anterior locations, no reliable differences were observed at centro-parietal and parietal locations.

When other specifics was compared to no specifics, the analysis revealed an interaction between condition, location and hemisphere $[F(2.2,30.5)=4.9 ; \mathrm{p}<0.05]$. Subsidiary analyses revealed that, at frontal sites only, there was an interaction between condition and hemisphere $[\mathrm{F}(1,14)=5.4 ; \mathrm{p}<0.05]$ : the other specifics effect is bigger than the no specifics effect, and this difference is greater on the right hemisphere. No other differences were observed. In sum, whilst name and other specifics exhibit no differences during the $300-500 \mathrm{~ms}$ time window, both conditions exhibit larger old/new effects than no specifics.

$500-700 m s$

When name was compared to other specifics, a main effect of condition was observed $[\mathrm{F}(1,14)=5.9 ; \mathrm{p}<0.05]$, reflecting a bigger effect for name than for other specifics.

When name was compared to no specifics, the analysis revealed a main effect of condition $[\mathrm{F}(1,14)=15.0 ; \mathrm{p}<0.01]$ along with interactions between condition and location $[F(1.4,20.3)=10.8 ; p<0.01]$, condition and site $[F(1.1,15.1)=4.5 ; p<0.05]$, 
condition, location and hemisphere $[\mathrm{F}(1.6,21.9)=8.6 ; \mathrm{p}<0.01]$, and between condition, location and site $[F(2.5,35.4)=6.3 ; p<0.01]$. Main effects of condition were observed at all 5 locations (frontal $[F(1,14)=17.3 ; p=0.001] ;$ fronto-central $[F(1,14)=17.4 ; p=$ $0.001]$; central $[F(1,14)=15.1 ; p<0.01]$; centro-parietal $[F(1,14)=11.3 ; p=0.005]$; parietal $[\mathrm{F}(1,14)=4.8 ; \mathrm{p}<0.05])$. There were interactions between condition and site at frontal $[F(1.1,15.5)=9.8 ; p<0.01]$, fronto-central $[F(1.1,16.3)=9.4 ; p<0.01]$ and central $[\mathrm{F}(1.3,17.7)=4.5 ; \mathrm{p}<0.05]$ sites, reflecting a bigger difference at superior sites. At parietal sites, there was an interaction between condition and hemisphere $[F(1,14)=$ 12.4; $\mathrm{p}<0.01]$, reflecting a bigger difference on the left hemisphere.

When other specifics was compared to no specifics, the analysis revealed a main effect of condition $[\mathrm{F}(1,14)=12.2 ; \mathrm{p}<0.01]$, reflecting a bigger effect for other specifics, and an interaction between condition, location and hemisphere $[\mathrm{F}(2.2,31.2)=10.1 ; \mathrm{p}<0.001]$. Main effects of condition were observed at frontal $[F(1,14)=10.6 ; p<0.01]$, frontocentral $[F(1,14)=12.5 ; p<0.01]$, central $[F(1,14)=12.6 ; p<0.01]$ and centro-parietal $[\mathrm{F}(1,14)=5.8 ; \mathrm{p}<0.05]$ sites. At centro-parietal sites, there was an interaction with hemisphere $[\mathrm{F}(1,14)=4.8 ; \mathrm{p}<0.05]$, reflecting a bigger difference on the left hemisphere, and at parietal sites, there was no main effect of condition but there was an interaction between condition and hemisphere $[\mathrm{F}(1,14)=12.8 ; \mathrm{p}<0.01]$, reflecting a bigger difference on the left hemisphere. In sum, during the $500-700 \mathrm{~ms}$ time window, the sizes of the old/new effects are graded such that name $>$ other specifics $>$ no specifics. 


\section{Topographic analyses}

As is clear from Fig. 3, the name and other specifics distributions have an anterior focus while the no specifics distribution has a posterior focus. To directly assess whether the apparent differences in distribution are statistically reliable, additional topographic comparisons were carried out. The data were rescaled and submitted to ANOVA with factors of condition (name vs. other specifics/name vs. no specifics/other specifics vs. no specifics), location (frontal/fronto-central/central/centro-parietal/parietal), hemisphere (left/right) and site (superior/medial/inferior).

$300-500 m s$

Pairwise comparisons between all three conditions revealed no significant differences in the topography of effects during the early time window.

$500-700 m s$

Comparison of the old/new effects for the name and other specifics conditions revealed no significant differences in the topography of effects.

Comparison of name and no specifics revealed significant interactions between condition and location $[\mathrm{F}(1.5,20.8)=10.2 ; \mathrm{p}<0.01]$, and between condition, hemisphere and site $[\mathrm{F}(1.4,19.8)=4.4 ; \mathrm{p}<0.05]$. As is evident from Fig. 3, these results reflect two principle differences between the old/new effects: first, the name effect exhibits an anterior distribution relative to the posterior distribution of the no specifics effect; and second, the 
name effect is larger over superior sites, particularly at right anterior electrodes, but this is not the case for the no specifics condition.

Finally, other specifics was compared to no specifics, revealing an interaction between condition, location and hemisphere $[\mathrm{F}(4,56)=8.7 ; \mathrm{p}<0.001]$. Again, as is evident from

Fig. 3, the other specifics condition is maximal over right hemisphere anterior electrodes but exhibits a left greater than right asymmetry over posterior electrodes, whereas the no specifics condition is maximal over right hemisphere posterior electrodes.

\section{Discussion}

The experience of 'I know your face but I can't remember your name' is common, but the neural correlates of recollection and familiarity for faces have not been widely investigated. Here, we separated ERPs according to whether participants could recognise faces with or without the retrieval of contextual information. We provide evidence for a neural correlate of familiarity that exhibits a posterior scalp distribution - quite different from that seen in most recognition memory studies. More importantly, we dissociate recollection and familiarity for faces, providing clear evidence for a neural correlate of recollection that exhibits an anterior maximum. Below we discuss this novel finding in relation to the traditional old/new effects, and in light of dual process accounts of recognition memory.

\section{Topographic dissociation between familiarity and recollection}

Assuming that performance supporting name and other specifics responses requires recollection, whereas performance supporting no specifics responses requires only 
familiarity, the data presented here show that recollection elicits a frontally focused old/new effect while familiarity elicits a more posterior old/new effect. To be clear, we do not claim a double dissociation between recollection and familiarity, with entirely separate effects in each case. Rather, old/new effects at the most anterior sites analysed were only found for recollection conditions, whereas old/new effects were identified for both familiarity and recollection conditions at more posterior sites.

Although positive going old/new effects are present over posterior electrodes for all 3 hit conditions, we are unable to tell whether this reflects the activity of a common set of neural generators. This question is of interest because it speaks to the issue of whether familiarity and recollection co-occur. If the posterior portion of the effect seen for name and other specifics reflected familiarity alone, then the amplitude of the 3 hit conditions would be expected to be equivalent. In fact, as can be seen in Fig. 2, over posterior electrodes the pattern was graded, with the name condition exhibiting greater positivity than other specifics, which was in turn greater than no specifics. Moreover, it seems likely that at least part of the posterior old/new effects seen for name and other specifics reflects simple propagation of the anterior recollection old/new effect across the scalp. Thus, the present findings leave open the possibility that the neural generators of familiarity are active whenever retrieval is successful. Regardless, our data clearly show that anterior activity accompanying recollection is topographically dissociable from posterior activity accompanying familiarity. 
The present findings are broadly consistent with data reported by Paller et al. (2000), in which faces presented without biographical information at study elicited a posterior old/new effect when recognised, whereas faces paired with biographical information at study elicited additional anterior activity when recognised. In their paper, the authors state that "effects at posterior locations $(\mathrm{Pz}$ and $\mathrm{Oz})$ were reliable for named and unnamed faces" and "effects at anterior locations $(\mathrm{Fz}$ and $\mathrm{Cz})$ were reliable only for named faces" (Paller et al., 2000, p.102). While specific details including electrode montage, analysis strategy and the precise boundaries between effects differ between our data and those of Paller et al., the same underlying anterior/posterior difference is present. Paller et al. argued that the posterior portion of the old/new effect reflects face recognition while the frontal portion reflects access to semantic information. The experiment employed a onestage old/new decision, and the authors were therefore unable to specify whether familiarity or recollection elicited the posterior activity. By contrast, the present results imply that the posterior portion of the face recognition old/new effect is actually a neural correlate of familiarity.

To our knowledge, unequivocally dissociable neural correlates of familiarity and recollection for faces have not been reported previously. In an attempt to characterise neural correlates of recollection and familiarity for faces, Yovel and Paller (2004) reported that the distribution of effects did not differ topographically. By contrast, our data identify a frontally maximum old/new effect for recollection, which is topographically distinct from the posterior old/new effect associated with familiarity. An obvious question that arises is why a topographic difference was not found by Yovel and 
Paller. One possibility is that our topographic dissociation reflects greater sensitivity to detect differences due to a denser electrode array. Another factor may be our experimental design, which included names as stimuli, and required relatively short study-test blocks to facilitate a sufficient level of performance to form ERPs. Perhaps more important may be the faces we used, which were masked of ears, hair and background; this difference in stimuli raises the possibility that different strategies were employed by participants across studies (thereby evoking different recollection effects). While the critical factor remains to be determined, our procedures reveal distinct neural correlates of familiarity and recollection.

\section{No mid frontal old/new effect when a face feels familiar}

As noted in the Introduction, previous studies have identified a mid frontal effect (300 $500 \mathrm{~ms}$ ) as the neural correlate of familiarity. One interesting feature of the present data concerns the prima fasciae topographic resemblance of the recollection old/new effect to the putative mid frontal index of familiarity, particularly during the $300-500 \mathrm{~ms}$ time window. We do not equate the two effects for several reasons. First, mid frontal familiarity effects are typically of equivalent magnitude across conditions where items are thought to be equally familiar (e.g. Curran, 2000), yet in the current data there are clear differences between hit conditions, with significantly larger effects for the name and other specifics conditions compared to no specifics (see Fig. 2). Second, there were no significant effects over frontal electrodes in the one condition where a correlate of familiarity would be most expected - the no specifics condition. Third, at a functional level, equating the anterior effect seen here with the typical mid frontal effect has an 
unpalatable theoretical implication - it implies that recollection during face recognition is primarily supported by familiarity.

Another possibility is that the recollection old/new effect seen here is an early manifestation of the well documented late right frontal old/new effect identified in many source memory paradigms (e.g. Wilding and Rugg, 1996) and considered to reflect postretrieval processing. We re-examined our data to consider this possibility (see Supplementary Material) and reject it for two reasons: first, from $500-700 \mathrm{~ms}$ the anterior effect is sensitive to the nature of the information recollected (with a bigger effect for name than for other specifics) whereas later right frontal activity is not sensitive to the nature of information recollected; second, the topographies of the two effects differ. Nevertheless, it remains possible that activity from 500 - 700ms represents a blend of mid frontal and late right frontal old/new effects. Of greatest importance, however, is the finding that familiarity for faces elicits a posterior old/new effect. Regardless of whether the anterior activity associated with recollection reflects the mid frontal effect, the late right frontal effect, a blend of the two, or a less well established correlate of recollection, familiarity was associated with a topographically dissociable posterior effect, which demonstrates that familiarity is not generically associated with the mid frontal old/new effect.

\section{A neural correlate of absolute familiarity?}

One motivation for examining face recognition was the possibility that unfamiliar faces allow absolute familiarity to be examined. This view is based upon a distinction between 
absolute and relative familiarity (see Mandler, 1980; Rugg et al., 1995). In a study-test paradigm, old items are relatively more familiar than new items because they have been encountered recently. If words are used as stimuli then all test items will have a baseline of familiarity because they have been encountered outside the experimental context; assessments of absolute familiarity will not be diagnostic of previous occurrence and so performance must be supported by sensitivity to relative changes in familiarity. In contrast, where previously unencountered stimuli are employed then assessments of absolute familiarity may be diagnostic of previous occurrence. By this view, the mid frontal effect would be considered an index of relative familiarity, whereas the parietal effect seen for faces reflects assessment of absolute familiarity.

One way to reconcile the present findings with those of Nessler et al. (2005), who identified a mid frontal effect in a continuous recognition paradigm with faces, is to conclude that task demands can promote a reliance on assessments of either relative or absolute familiarity, each of which is associated with a distinct neural correlate. By this view, performance on a continuous recognition paradigm may be associated with assessments of relative familiarity, eliciting a mid frontal effect, whereas traditional study-test paradigms using faces may allow greater reliance on absolute familiarity possibly due to the greater opportunity for encoding that is available - and elicits a parietal old/new effect associated with familiarity.

Regardless of whether performance in the no specifics condition is supported by absolute or relative familiarity, the present data are consistent with a dual process account. Not 
only are topographically dissociable effects elicited by familiarity and recollection, but the effects differ in their time course, with the frontal old/new effect associated with recollection appearing to last longer (see Fig. 2, and Supplementary Material).

Functionally, face recognition performance can be separated according to whether familiarity or recollection supports retrieval, and at this level face recognition is no different from any other kind of stimulus recognition in providing evidence for dual process theory. At a neural level, however, a different pattern of activity seems to support face recognition than is typically characteristic of episodic retrieval - at least under the conditions employed here. Whether features such as the particular structure of the paradigm or the characteristics of the stimuli employed determine the pattern of effects remains to be seen. Regardless, if dual process theories are to explain recognition memory at both functional and neural levels they need to accommodate the differences between the old/new effects elicited in the present paradigm and those more commonly associated with familiarity and recollection. To our knowledge, no current dual process model distinguishes between the retrieval processes engaged by different types of paradigm or stimulus.

\section{Conclusion}

We examined the neural correlates associated with the experience of 'I know your face but I can't remember your name', identifying topographically dissociable ERP old/new effects associated with recollection and familiarity. The current data are suggestive of the material specificity of the ERP old/new effects: the effects seen here for faces do not match those typically seen in studies of word recognition. Any claims of material 
specificity are premature, of course, and must await evidence from paradigms directly comparing stimulus materials. Regardless, the present finding raises the possibility that there may be more than one route to the feeling of familiarity engendered by a stimulus, depending on whether assessment of relative or absolute familiarity is diagnostic of previous occurrence. Further research investigating the differences between various types of stimuli on the neural correlates of recognition memory promises to aid in elucidating the functional characteristics of ERP old/new effects, and in assessing the generalisability of dual process accounts. Fundamentally, these new data provide clear evidence that the ERP old/new effect does not provide a generic index of retrieval processing under all circumstances.

\section{Acknowledgement}

Thanks to Nina MacKenzie for helping to make the auditory stimuli used in this experiment.

\section{References}

Allan, K., Wilding, E.L., Rugg, M.D., 1998. Electrophysiological evidence for dissociable processes contributing to recollection. Acta Psychologica 98, 231-252. Atkinson, R.C., Juola, J.F., 1974. Search and Decision Processes in Recognition Memory. In: Krantz, D.H., Atkinson, R.C., Luce, R.D. (Eds.) Contemporary Developments in Mathematical Psychology Volume 1: Learning, Memory and Thinking. Freeman, San Francisco, pp. 243-293. 
Curran, T., 2000. Brain potentials of recollection and familiarity. Memory and Cognition 20, 923-938.

Curran, T., Cleary, A.M., 2003. Using ERPs to dissociate recollection from familiarity in picture recognition. Cognitive Brain Research 15, 191-205.

Donaldson, D.I., Rugg, M.D., 1998. Recognition memory for new associations:

Electrophysiological evidence for the role of recollection. Neuropsychologia 36, 377-395.

Donaldson, D.I., Allan, K., Wilding, E.L. 2002. Fractionating episodic memory retrieval using event-related potentials. In: Parker, A., Wilding, E.L., Bussey, T. (Eds.). The Cognitive Neuroscience of Memory: Encoding and Retrieval. Psychology Press, Hove, pp 39-58.

Donaldson, W., 1996. The role of decision processes in remembering and knowing. Memory and Cognition 24, 523-533.

Greve, A, Van Rossum, M., Donaldson, D.I., in press. Investigating the functional interaction between semantic and episodic memory: Convergent behavioural and electrophysiological evidence for the role of familiarity. NeuroImage. Jasper, H.A., 1958. The ten-twenty system of the international federation. Electroencephalography and Clinical Neurophysiology 10, 371-375. Mandler, G., 1980. Recognizing: The judgement of previous occurrence. Psychological Review 87, $252-271$.

McCarthy, G., Wood, C.C., 1985. Scalp distributions of event-related potentials: An ambiguity associated with analysis of variance models. Clinical Neurophysiology 62 , 203-208. 
Mecklinger, A., 2000. Interfacing mind and brain: A neurocognitive model of recognition memory. Psychophysiology 37, 565-582.

Mecklinger, A., von Crammon, D.Y., Matthes-von Crammon, G., 1998. Event-related potential evidence for a specific recognition memory deficit in adult survivors of cerebral hypoxia. Brain 121, 1919-1935.

Nessler, D., Mecklinger, A., Penney, T.B., 2005. Perceptual fluency, semantic familiarity and recognition-related familiarity: An electrophysiological exploration. Cognitive Brain Research 22, 265-288.

Paller, K.A., Gonsalves, B., Grabowecky, M., Bozic, V.S., Yamada, S., 2000.

Electrophysiological correlates of recollecting faces of known and unknown individuals. NeuroImage 11, 98-110.

Rhodes, S.M., Donaldson, D.I., in press. Electrophysiological evidence for the influence of unitization on the processes engaged during episodic retrieval: Enhancing familiarity based remembering. Neuropsychologia.

Rugg, M.D., Cox, C.J.C., Doyle, M.C., Wells, T., 1995. Event-related potentials and the recollection of low and high frequency words. Neuropsychologia 33, 471-484.

Rugg, M.D., Mark, R.E., Walla, P., Schloerscheidt, A.M., Birch, C.S., Allan, K., 1998. Dissociation of the neural correlates of implicit and explicit memory. Nature 392, 595598.

Schloerscheidt, A.M., Rugg, M.D., 2004. The impact of change in stimulus format on the electrophysiological indices of recognition. Neuropsychologia 42, 451-466.

Tiddeman, B., Burt, D.M., Perrett, D., 2001. Computer graphics in facial perception research. IEEE Computer Graphics and Applications 21, 42-50. 
Tsivilis, D., Otten, L.J., Rugg, M.D., 2001. Context effects on the neural correlates of recognition memory: An electrophysiological study. Neuron 31, 497-505.

Tulving, E., 1985. How many memory systems are there? American Psychologist 40, 385-398.

Wilding, E.L., Rugg, M.D., 1996. An event-related potential study of recognition memory with and without retrieval of source. Brain 119, 889-905.

Yonelinas, A.P., 1994. Receiver-operating characteristics in recognition memory:

Evidence for a dual process model. Journal of Experimental Psychology: Learning, Memory and Cognition 20, 1341-1354.

Yonelinas, A.P., 2002. The nature of recollection and familiarity: A review of 30 years of research. Journal of Memory and Language 46, 441-517.

Yovel, G., Paller, K.A., 2004. The neural basis of the butcher-on-the-bus phenomenon:

When a face seems familiar but is not remembered. NeuroImage 21, 789-800. 


\section{Figure Legends}

Figure 1. Procedure on each trial at study and test: On each study trial, a grey fixation cross was replaced after $1000 \mathrm{~ms}$ by a face, which was presented for $2000 \mathrm{~ms}$; coincidental with face onset was an auditory name presentation. After face offset, participants were prompted to rate the fit between face and name with a binary judgement, i.e. 'good fit' or 'bad fit'. On each test trial, a grey fixation cross was replaced after $1500 \mathrm{~ms}$ by a face, which was presented for 500ms. Test faces were either old (studied) or new (unstudied). A black screen followed face offset, and remained for $2000 \mathrm{~ms}$ during which time participants pressed either 'old' or 'new'. If a face was endorsed as 'new' then the trial terminated; if a face was endorsed as 'old' then a screen prompted participants to introspect upon the quality of their memory for the study episode. If face recognition was accompanied by name retrieval then participants pressed 'name' and were then asked to say the name that they could recall. The experimenter pressed a button to code the response as either correct or incorrect, which terminated the trial. If face recognition was accompanied by the retrieval of other specific information from the study episode then participants pressed 'other specifics', which terminated the trial. If face recognition was not accompanied by retrieval of specific information from the study episode then participants pressed 'no specifics', which terminated the trial.

Figure 2. Old/new effects: ERP waveforms are shown for midline frontal and parietal electrodes. ERPs are shown for: correct responses to old faces where participants correctly supplied the name that was paired with the face at study ('name'); correct 
responses to old faces where participants recollected information other than the name ('other specifics'); correct responses to old faces where participants did not recollect any information from the study episode ('no specifics'); along with correct responses to new faces ('CR'). Scale bars indicate the magnitude of activity (in microvolts) and the timecourse of activity (in milliseconds). The difference between 'name' and 'CR' waveforms is greater at the frontal electrode; the difference between 'other specifics' and 'CR' waveforms is also greater at the frontal electrode; but in contrast, the difference between 'no specifics' and 'CR' is greater at the parietal electrode.

Figure 3. Topographic distribution of recollection and familiarity: Each cartoon shows the distribution of the difference between correctly recognised old items and correctly rejected new items. The front of the head is at the top of each map, and the left hemisphere is on the left-hand side. Each dot represents a recording electrode. The scale bars indicate the range of activity (in microvolts), and are plotted separately for each condition. The distribution of the old/new effect has a clear anterior focus for the 'name' and 'other specifics' retrieval conditions associated with recollection, but a posterior focus for the 'no specifics' condition associated with familiarity. 


\section{Footnote}

1. In fact, we initially analysed the evolution of the old/new effects by segmenting the data into $100 \mathrm{~ms}$ time windows. These preliminary analyses revealed that the old/new differences only became significant from $400-500 \mathrm{~ms}$ post-stimulus in all 3 conditions. In the name and other specifics conditions, the old/new effects remained significant until 800ms post-stimulus; in the no specifics condition, the old/new effect remained significant until $600 \mathrm{~ms}$ post-stimulus. Although we acknowledge the statistical concerns that arise when choosing time windows based on inspection of the data, we originally analysed the effects over $400-600 \mathrm{~ms}$ and $600-800 \mathrm{~ms}$ time windows. The results of this analysis are provided as Supplementary Material. Whilst the use of non-standard time windows makes comparison with other data sets more difficult, we believe that it provides a more precise characterization of the effects presented here. 
Table 1: Behavioural Results

\begin{tabular}{|lccc|}
\hline & Name & Other Specifics & No Specifics \\
\% Hits & 32.8 & 34.4 & 32.8 \\
Standard deviation & $\mathbf{1 2 . 2}$ & $\mathbf{1 3 . 9}$ & $\mathbf{1 5 . 6}$ \\
Response Time (ms) & 1417 & 1511 & 1599 \\
Standard deviation & $\mathbf{2 6 7}$ & $\mathbf{2 9 5}$ & $\mathbf{3 2 5}$ \\
\hline
\end{tabular}


Table 2: Results of ANOVA for the $300-500 \mathrm{~ms}$ time window

\section{NAME v. CORRECT REJECTION}

Old/New

F

FC

C

CP

P $\quad \mathrm{F}(1,14)=15.9 ; \mathrm{p}=0.001$
Old/New * Hemisphere

$\mathrm{n} / \mathrm{s}$

$\mathrm{n} / \mathrm{s}$

$\mathrm{n} / \mathrm{s}$

$\mathrm{n} / \mathrm{s}$

$\mathrm{n} / \mathrm{s}$
Old $/$ New * Site

$F(1.2,16.2)=8.0 ; p=0.01$

$\mathrm{F}(1.4,19.0)=12.2 ; \mathrm{p}=0.001$

$\mathrm{F}(1.1,15.4)=8.2 ; \mathrm{p}=0.01$

$\mathrm{n} / \mathrm{s}$

$\mathrm{n} / \mathrm{s}$
Old/New * Hemisphere * Site

$\mathrm{n} / \mathrm{s}$

$\mathrm{n} / \mathrm{s}$

$\mathrm{n} / \mathrm{s}$

$\mathrm{n} / \mathrm{s}$

$\mathrm{n} / \mathrm{s}$

\section{OTHER SPECIFICS v. CORRECT REJECTION}

\section{Old/New}

F

FC

C

CP

$\mathbf{P}$

$$
\mathrm{F}(1,14)=9.0 ; \mathrm{p}<0.01
$$

$\mathrm{F}(1,14)=10.1 ; \mathrm{p}<0.01$

$\mathrm{F}(1,14)=7.4 ; \mathrm{p}<0.05$

$\mathrm{F}(1,14)=7.6 ; \mathrm{p}<0.05$

$\mathrm{F}(1,14)=7.0 ; \mathrm{p}<0.05$
Old/New * Hemisphere

$\mathrm{n} / \mathrm{s}$

$\mathrm{n} / \mathrm{s}$

$\mathrm{n} / \mathrm{s}$

$\mathrm{n} / \mathrm{s}$

$\mathrm{n} / \mathrm{s}$
Old/New * Site

$\mathrm{n} / \mathrm{s}$

$\mathrm{n} / \mathrm{s}$

$\mathrm{n} / \mathrm{s}$

$\mathrm{n} / \mathrm{s}$

$\mathrm{n} / \mathrm{s}$
Old/New * Hemisphere * Site

$\mathrm{n} / \mathrm{s}$

$\mathrm{n} / \mathrm{s}$

$\mathrm{n} / \mathrm{s}$

$\mathrm{n} / \mathrm{s}$

$\mathrm{n} / \mathrm{s}$

\section{NO SPECIFICS v. CORRECT REJECTION}

Old/New

F

FC

C

CP

$\mathbf{P}$
Old/New * Hemisphere

$\mathrm{n} / \mathrm{s}$ $\mathrm{n} / \mathrm{s}$

$\mathrm{n} / \mathrm{s}$

$\mathrm{n} / \mathrm{s}$

$\mathrm{n} / \mathrm{s}$

$\mathrm{n} / \mathrm{s}$
Old/New * Site

$\mathrm{n} / \mathrm{s}$

$\mathrm{F}(2,28)=3.5 ; \mathrm{p}<0.05$

$F(2,28)=3.7 ; p<0.05$

$\mathrm{n} / \mathrm{s}$

$\mathrm{n} / \mathrm{s}$
Old/New * Hemisphere * Site

$\mathrm{n} / \mathrm{s}$

$\mathrm{n} / \mathrm{s}$

$\mathrm{n} / \mathrm{s}$

$\mathrm{n} / \mathrm{s}$

$\mathrm{n} / \mathrm{s}$

$\mathrm{F}=$ frontal; $\mathrm{FC}=$ fronto-central $\mathrm{C}=$ central $; \mathrm{CP}=$ centro-parietal; $\mathrm{P}=$ parietal 
Table 3: Results of ANOVA for the $500-700 \mathrm{~ms}$ time window

\section{NAME v. CORRECT REJECTION}

Old/New

F

FC

C

CP

P $\quad \mathrm{F}(1,14)=43.4 ; \mathrm{P}<0.001$
Old/New * Hemisphere

$F(1,14)=17.1 ; p=0.001$

$\mathrm{F}(1,14)=6.3 ; \mathrm{p}<0.05$

$\mathrm{n} / \mathrm{s}$

$\mathrm{n} / \mathrm{s}$

$\mathrm{n} / \mathrm{s}$
Old/New * Site

$\mathrm{F}(1.1,15.2)=5.9 ; \mathrm{p}<0.05$

$\mathrm{F}(1.2,17.0)=8.2 ; \mathrm{p}<0.01$

$\mathrm{F}(1.0,14.5)=6.0 ; \mathrm{p}<0.05$

$\mathrm{n} / \mathrm{s}$

$\mathrm{n} / \mathrm{s}$
Old/New * Hemisphere * Site

$\mathrm{n} / \mathrm{s}$
$\mathrm{n} / \mathrm{s}$
$\mathrm{n} / \mathrm{s}$
$\mathrm{n} / \mathrm{s}$
$\mathrm{n} / \mathrm{s}$

\section{OTHER SPECIFICS v. CORRECT REJECTION}

\section{Old/New}

F

FC

C

CP

$\mathbf{P}$

$$
\mathrm{F}(1,14)=6.4 ; \mathrm{p}<0.05
$$

$\mathrm{F}(1,14)=7.6 ; \mathrm{p}<0.05$

$\mathrm{F}(1,14)=9.1 ; \mathrm{p}<0.01$

$\mathrm{F}(1,14)=12.8 ; \mathrm{p}<0.01$

$\mathrm{F}(1,14)=13.9 ; \mathrm{p}<0.01$
Old/New * Hemisphere

$\mathrm{F}(1,14)=5.5 ; \mathrm{p}<0.05$

$\mathrm{n} / \mathrm{s}$

$\mathrm{n} / \mathrm{s}$

$\mathrm{n} / \mathrm{s}$

$\mathrm{n} / \mathrm{s}$
Old/New * Site

$\mathrm{n} / \mathrm{s}$

$\mathrm{n} / \mathrm{s}$

$\mathrm{n} / \mathrm{s}$

$\mathrm{n} / \mathrm{s}$

$\mathrm{n} / \mathrm{s}$
Old/New * Hemisphere * Site

$$
\mathrm{F}(2,28)=3.5 ; \mathrm{p}<0.05
$$

$\mathrm{n} / \mathrm{s}$

$\mathrm{n} / \mathrm{s}$

$\mathrm{n} / \mathrm{s}$

$\mathrm{n} / \mathrm{s}$

\section{NO SPECIFICS v. CORRECT REJECTION}

Old/New

F

FC

C

CP

$\mathbf{P}$
Old/New * Hemisphere

$\mathrm{F}(1,14)=5.2 ; \mathrm{p}<0.05$

$\mathrm{n} / \mathrm{s}$

$\mathrm{F}(1,14)=4.8 ; \mathrm{p}<0.05$

$\mathrm{n} / \mathrm{s}$

$\mathrm{n} / \mathrm{s}$
Old/New * Site

$\mathrm{n} / \mathrm{s}$

$\mathrm{n} / \mathrm{s}$

$\mathrm{n} / \mathrm{s}$

$\mathrm{n} / \mathrm{s}$

$\mathrm{n} / \mathrm{s}$
Old/New * Hemisphere * Site

$\mathrm{n} / \mathrm{s}$

$\mathrm{n} / \mathrm{s}$

$\mathrm{F}(1.4,19.7)=6.2 ; \mathrm{p}<0.05$

$\mathrm{n} / \mathrm{s}$

$\mathrm{n} / \mathrm{s}$

$\mathrm{F}=$ frontal; $\mathrm{FC}=$ fronto-central $\mathrm{C}=$ central $; \mathrm{CP}=$ centro-parietal; $\mathrm{P}=$ parietal 
Figure 1: Procedure

\section{Study Trial}

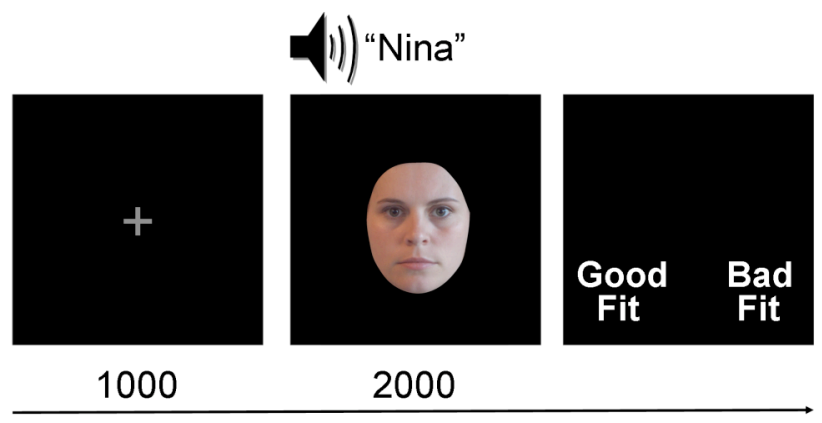

\section{Test Trial}

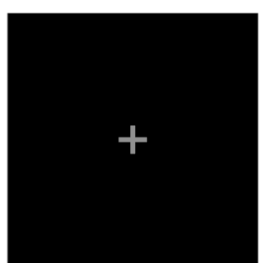

1500

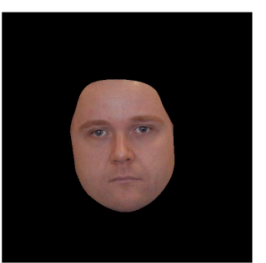

500

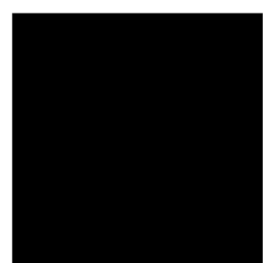

2000

'Old' or 'New'
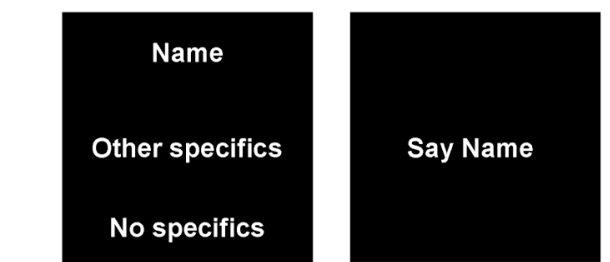

If 'Old'

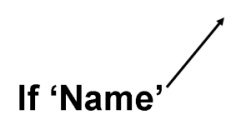


Figure 2
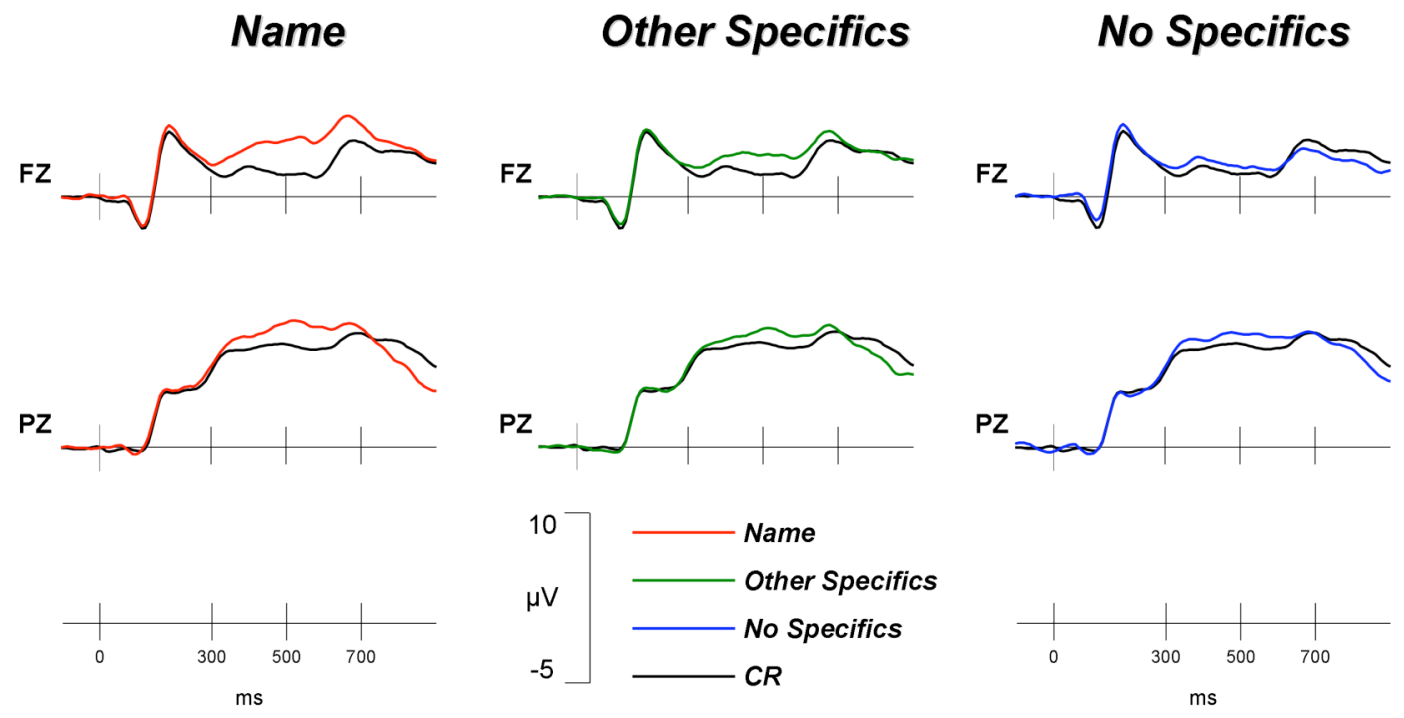
Figure 3
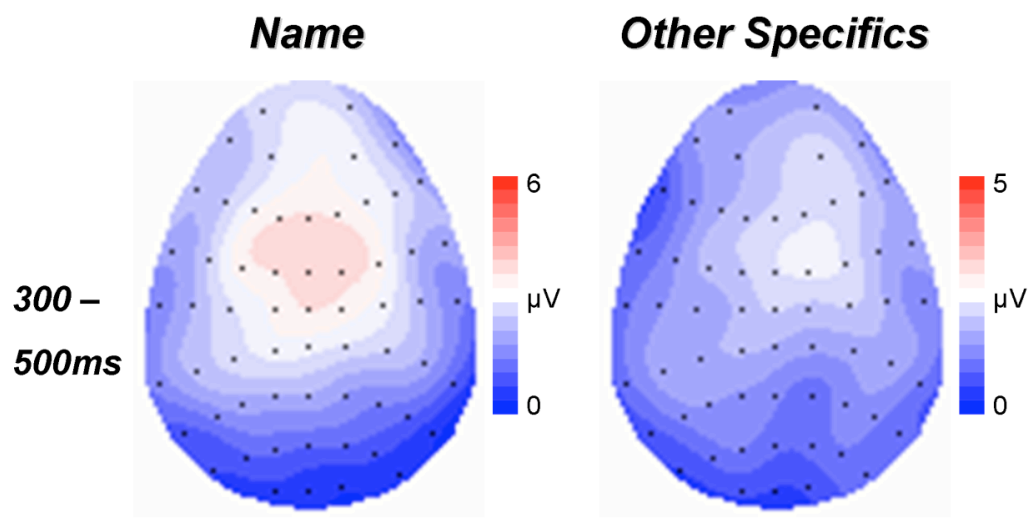

\section{No Specifics}
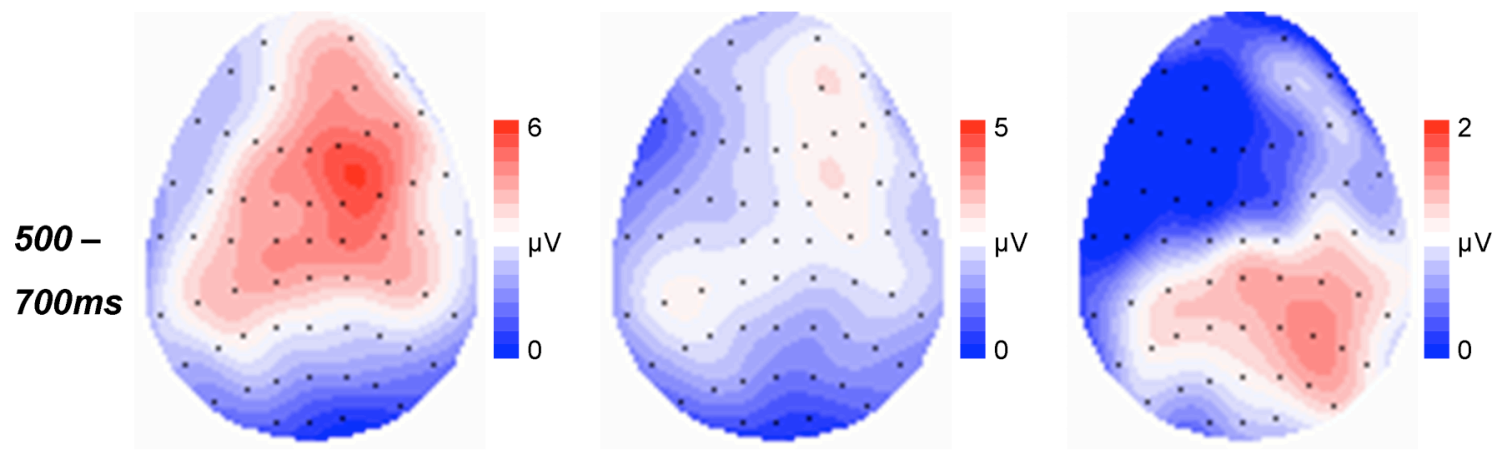


\section{Supplementary Material}

We investigated whether neural correlates of familiarity and recollection could be identified in a study-test paradigm using faces as retrieval cues. The original analyses were based on the quantification of waveforms based on preliminary inspection of the data rather than on a priori time windows. We believe that the analysis of activity from $400-600 \mathrm{~ms}$ provides the most accurate characterization of the neural correlate of familiarity, and so the results of the original analyses are presented here.

To characterize the pattern of old/new effects, data were segmented into $100 \mathrm{~ms}$ time windows, and the evolution of the old/new effects was anlaysed for each condition. These preliminary analyses revealed that the old/new differences became significant from 400 $500 \mathrm{~ms}$ in all 3 conditions. In the name and other specifics conditions, the old/new effects remained significant until $800 \mathrm{~ms}$; in the no specifics condition, the old/new effect remained significant until $600 \mathrm{~ms}$. To best capture the old/new effects in all 3 conditions, waveforms were quantified into 2 time windows from 400 - 600ms and from 600 $800 \mathrm{~ms}$. These latencies represent a slight temporal shift from the standard $300-500 \mathrm{~ms}$ and $500-700 \mathrm{~ms}$ time windows used to investigate the old/new effect during typical word recognition studies. It is, of course, unsurprising that the exact time course of effects is delayed in the case of faces given the complexity of face stimuli relative to words. Our choice of latency regions was therefore based upon the preliminary analyses of the old/new effects described above. 
Data were first submitted to ANOVA with factors of old/new, location (frontal/frontocentral/central/centro-parietal/parietal), hemisphere (left/right) and site (superior/medial/inferior). Significant differences were followed by subsidiary ANOVA performed on data from each location separately.

Name old/new effect, $400-600 \mathrm{~ms}$

The analysis revealed a main effect of old $/$ new $[F(1,14)=57.7 ; \mathrm{p}<0.001]$ and interactions between old/new and location $[\mathrm{F}(1.4,19.0)=7.1 ; \mathrm{p}=0.01]$, old $/$ new and site $[F(1.1,15.1)=10.3 ; p=0.005]$, old $/$ new, location and hemisphere $[F(1.4,19.2)=5.0 ; p<$ $0.05]$, and between old $/$ new, location and site $[\mathrm{F}(3.3,45.5)=5.0 ; \mathrm{p}<0.01]$. The interactions are due to the old/new differences being greatest at anterior, superior sites, particularly on the right hemisphere. Subsidiary ANOVA (see Table 1) revealed significant effects at all 5 locations, and examination of the data revealed that the name old/new effect was maximal at FC2.

\section{***INSERT TABLE 1 ABOUT HERE***}

Other specifics old/new effect, $400-600 \mathrm{~ms}$

The analysis revealed a main effect of old $/$ new $[F(1,14)=17.7 ; p=0.001]$ and interactions between old/new, location and hemisphere $[\mathrm{F}(1.6,23.0)=5.7 ; \mathrm{p}<0.05]$ and between old/new, location and site $[\mathrm{F}(3.6,50.5)=2.8 ; \mathrm{p}=0.042]$. These interactions are due to the old/new differences being greatest at anterior, superior sites on the right 
hemisphere. Subsidiary ANOVA (see Table 1) revealed significant effects at all 5 locations, and the other specifics old/new effect was maximal at FC2.

No specifics old/new effects, $400-600 \mathrm{~ms}$

The analysis revealed a main effect of old $/$ new $[F(1,14)=11.5 ; \mathrm{p}<0.01]$ and an interaction between old $/$ new, hemisphere and site $[F(1.4,19.2)=4.7 ; p<0.05]$, which reflects greater old/new differences at superior sites on the right hemisphere. To ensure consistent analyses across conditions, subsidiary ANOVA were performed on the data from each location separately (see Table 1). In contrast to the findings for name and other specifics, these analyses revealed no significant differences at frontal sites. However, the old/new effect was significant at more posterior locations. Examination of the data revealed that the no specifics old/new effect was maximal at CPZ.

Comparison across conditions, $400-600 \mathrm{~ms}$

Figure 1 shows the distribution of the old/new effects (based on the difference between each hit condition and the correct rejection condition) from $400-600 \mathrm{~ms}$. As is clear from the Figure, and consistent with the foregoing analyses, the name and other specifics distributions have an anterior focus while the no specifics distribution has a posterior focus. Subtraction waveforms were computed for all three conditions allowing direct comparison of the relative sizes of the old/new differences. The data were submitted to ANOVA with factors of condition (name/other specifics/no specifics), location (frontal/fronto-central/central/centro-parietal/parietal), hemisphere (left/right) and site (superior/medial/inferior). The analysis revealed a main effect of condition $[\mathrm{F}(2,28)=$ 
$10.7 ; \mathrm{p}<0.001]$ and an interaction between condition and location $[\mathrm{F}(2.3,32.7)=5.4 ; \mathrm{p}<$ 0.01], confirming the presence of differences in the anterior-posterior maxima of effects across conditions. These differences were further investigated using pairwise comparisons.

\section{***INSERT FIGURE 1 ABOUT HERE***}

Comparison of name and other specifics revealed a main effect of condition $[\mathrm{F}(1,14)=$ $6.6 ; \mathrm{p}<0.05]$, reflecting a larger old/new effect for name than for other specifics. No significant interactions involving condition were found, suggesting that the name and other specifics effects differ quantitatively, but not qualitatively. Comparison between name and no specifics revealed a main effect of condition $[\mathrm{F}(1,14)=15.2 ; \mathrm{p}<0.001]$, along with interactions between condition and location $[F(1.4,19.0)=9.6 ; p=0.003]$ and between condition and site $[\mathrm{F}(1.1,15.2)=5.3 ; \mathrm{p}=0.033]$. These interactions reflect a larger old/new effect for name than for no specifics, augmented at anterior locations and at superior sites, suggesting that the name and no specifics old/new effects differ qualitatively. Analysis comparing other specifics and no specifics revealed a main effect

of condition $[F(1,14)=7.2 ; \mathrm{p}=0.018]$ and an interaction between condition, location and hemisphere $[\mathrm{F}(2.6,36.2)=9.2 ; \mathrm{p}<0.001]$. The other specifics old/new effect is larger than the no specifics old/new effect at frontal sites on the left hemisphere, again suggesting that the other specifics and no specifics old/new effects are qualitatively distinct. 
Topographic analysis, $400-600 \mathrm{~ms}$

The amplitude analyses revealed quantitative (but not qualitative) differences in distribution between the name and other specifics old/new effects. Further, the analyses suggest that these two conditions exhibited a different distribution from the no specifics old/new effect. To confirm that these differences in distribution do not result from the confounding effects of differences in amplitude, additional analyses were performed on normalized data.

Rescaled data from the $400-600 \mathrm{~ms}$ time window were submitted to ANOVA with factors of condition (name/other specifics/no specifics), location (frontal/frontocentral/central/centro-parietal/parietal), hemisphere (left/right) and site (superior/medial/inferior). The analysis revealed an interaction between condition and location $[F(1.7,24.0)=3.7 ; p<0.05]$, confirming the presence of differences in distribution across conditions. Subsidiary analyses revealed no differences between the name and other specifics distributions. By contrast, comparison of name and no specifics revealed interactions between condition and location $[\mathrm{F}(1.3,18.3)=5.5 ; \mathrm{p}<0.05]$ and between condition, hemisphere and site $[\mathrm{F}(2,28)=4.1 ; \mathrm{p}<0.05]$. Finally, other specifics was compared to no specifics and an interaction between condition, location and hemisphere $[\mathrm{F}(2.2,30.9)=6.4 ; \mathrm{p}<0.01]$ was found. These interactions implicate a qualitative difference in the distribution of the no specifics old/new effect when compared to the distributions of both the name and other specifics old/new effects. As is clear from Figure 1, the name and other specifics conditions elicit old/new effects that are maximal 
over anterior electrodes, whereas the no specifics condition elicits an old/new maximal over posterior electrodes.

Old $>$ New Effects, $600-800 \mathrm{~ms}$

Further evidence of dissociation between the recollection and familiarity conditions comes from analysis of amplitude data from $600-800 \mathrm{~ms}$. Data were submitted to ANOVA with factors of old/new, location (frontal/fronto-central/central/centroparietal/parietal), hemisphere (left/right) and site (superior/medial/inferior); the analysis of the name condition revealed a main effect of old $/$ new $[\mathrm{F}(1,14)=6.05 ; \mathrm{p}<0.05]$ along with interactions between old/new, location and hemisphere $[\mathrm{F}(1.6,22.0)=14.2 ; \mathrm{p}<$ $0.001]$, old $/$ new, location and site $[\mathrm{F}(3.4,48.0)=4.9 ; \mathrm{p}<0.01]$ and between interaction between old/new, location, hemisphere and site $[\mathrm{F}(4.2,59.3)=3.8 ; \mathrm{p}<0.01]$. These interactions reflect the old/new effect being largest at anterior locations, particularly on the right hemisphere and at superior sites. The analysis of the other specifics condition revealed interactions between old/new, location and hemisphere $[\mathrm{F}(1.4,19.9)=7.6 ; \mathrm{p}<$ $0.01]$ and between old/new, location, hemisphere and site $[F(4.7,66.1)=2.9 ; \mathrm{p}=0.005]$. These interactions also reflect the anterior focus of the old/new effect, which is larger on the right hemisphere at superior sites. In contrast, the no specifics condition was associated with a reversal at frontal sites, with the waveform for correct rejections significantly greater than the waveform for hits. The ANOVA revealed interactions between old $/$ new and hemisphere $[\mathrm{F}(1,14)=5.7 ; \mathrm{p}<0.05]$ and between old $/$ new, hemisphere and site $[F(2,28)=4.7 ; p<0.05]$ reflecting the presence of a negativity for hits relative to correct rejections, particularly on the left hemisphere and at superior sites. 
This negativity is not the focus of this paper and so will not be considered further. The old $>$ new pattern observed at posterior sites for no specifics in the $400-600 \mathrm{~ms}$ time window was not present from $600-800 \mathrm{~ms}$, and thus the analysis of data from the later time window demonstrates that the frontally distributed name and other specifics old/new effects are significant from $400-800 \mathrm{~ms}$, while the parietally distributed no specifics old/new effect is only significant from $400-600 \mathrm{~ms}$.

\section{***INSERT FIGURE 2 ABOUT HERE***}

\section{Old/new Effects, 400 - 1400ms post-stimulus}

One concern about the current findings is that the frontal effects we report may reflect the late right frontal old/new effect reported in many source memory paradigms and considered to reflect post-retrieval processing. Although not the primary aim of this paper, we lengthened the epoch and analysed data from the $800-1400 \mathrm{~ms}$ latency to assess whether the old/new effects associated with recollection can be differentiated from the late right frontal effect. Figure 2 shows ERPs from representative electrode sites that show different patterns of activity at superior frontal and right frontal sites. As can be seen, the waveforms vary in a graded manner at FC2 with name more positive than other specifics, while at AF8 the name and other specifics waveforms are overlaid. These observations receive statistical support when comparisons are made between name and other specifics during the $400-600 \mathrm{~ms}, 600-800 \mathrm{~ms}, 800-1000 \mathrm{~ms}, 1000-1200 \mathrm{~ms}$ and $1200-1400 \mathrm{~ms}$ time windows. Data from frontal sites were submitted to ANOVA with factors of condition (name/other specifics), hemisphere (left/right) and site 
(superior/medial/inferior). In the $400-600 \mathrm{~ms}$ period, the analysis revealed a main effect of condition such that name is more positive than other specifics $[\mathrm{F}(1,14)=6.2 ; \mathrm{p}<$ 0.05], while there were no reliable differences between the 2 recollection conditions in any latency during the $600-1400 \mathrm{~ms}$ period. This finding demonstrates that the recollection-elicited activity from $400-600 \mathrm{~ms}$ is modulated differently from the late right frontal component.

To assess whether different neural generators are responsible for the activity seen across early and late latencies, topographic analyses were performed on normalized subtraction data from the name condition at frontal electrodes (see Fig. 2). Data were submitted to ANOVA with factors of latency (400-600/600-800/800-1000/1000-1200/1200-1400), hemisphere (left/right) and site (superior/medial/inferior). The analysis revealed an interaction between latency and site $[\mathrm{F}(1.8,25.2)=6.9 ; \mathrm{p}=0.005]$, reflecting the superior distribution of the effect from $400-800 \mathrm{~ms}$ combined with the inferior distribution of the effect during the $800-1400 \mathrm{~ms}$ period. Comparisons between the $400-600 \mathrm{~ms}$ latency with all other latencies revealed a difference between the $400-600 \mathrm{~ms}$ and $600-800 \mathrm{~ms}$ (interactions between latency and hemisphere $[\mathrm{F}(1,14)=8.8 ; \mathrm{p}=0.01]$ and between latency, hemisphere and site $[\mathrm{F}(1.5,21.1)=4.8 ; \mathrm{p}<0.05])$, suggesting that the $600-$ $800 \mathrm{~ms}$ period captures a blend of early and late effects. More importantly for present purposes, comparisons between the $400-600 \mathrm{~ms}$ and $800-1400 \mathrm{~ms}$ revealed interactions between latency and site $(400-600$ v. $800-1000: \mathrm{F}(1.1,15.7)=10.4 ; \mathrm{p}<0.01 ; 400-$ $600 \mathrm{v} 1000-1200: \mathrm{F}(1.1,15.1)=10.1 ; \mathrm{p}=0.005 ; 400-600 \mathrm{v} 1200-1400: \mathrm{F}(1.2,16.2)=$ 11.7; $\mathrm{p}<0.01$ ), due to the inferior distribution of the effects later in the epoch. This 
pattern of results demonstrates that, whatever their functional interpretations, the effects identified during the $400-600 \mathrm{~ms}$ and later latency periods are both functionally and topographically dissociable. 


\section{Appendix}

This table lists the names used as study phase stimuli. Names were taken from US social security records (http://www.ssa.gov/OACT/babynames/1999/top1000of70s.html), and represent the most common names chosen for children born in the 1970s. To enhance ecological validity, some Scottish names supplemented those taken from the social security records.

\begin{tabular}{|c|c|c|c|c|c|}
\hline Aaron & Chad & Flo & Joseph & Misty & Sebastian \\
\hline Adam & Charles & Frances & Joshua & Monica & Seumas \\
\hline Alana & Charlotte & Frank & Juan & Monty & Shane \\
\hline Alasdair & Cheryl & Fraser & Julie & Nancy & Shannon \\
\hline Alexander & Christina & Gary & Justin & Nathan & Sharon \\
\hline Alison & Christine & Gemma & Karen & Nicholas & Simon \\
\hline Amanda & Christopher & George & Kathleen & Nicole & Sophie \\
\hline Amber & Christy & Geraldine & Keith & Nina & Stacy \\
\hline Amy & Corey & Glenn & Kelly & Oliver & Stanley \\
\hline Andrea & Craig & Gordon & Kendra & Olivia & Stephanie \\
\hline Andrew & Crystal & Graham & Kenneth & Pamela & Steven \\
\hline Angela & Cynthia & Gregory & Kevin & Patricia & Susan \\
\hline Ann & Dana & Harry & Kimberly & Patrick & Tammy \\
\hline Annette & Daniel & Heather & Kristin & Patsy & Tanya \\
\hline Anthony & Danielle & Heidi & Larry & Paul & Tara \\
\hline April & David & Hilda & Laura & Percy & Teresa \\
\hline Archie & Dawn & Holly & Lauren & Peter & Terry \\
\hline Arnold & Dean & Hugh & Leonard & Phillip & Thomas \\
\hline Audrey & Deborah & Ian & Leslie & Rachel & Tiffany \\
\hline Barbara & Denise & Imogen & Lianne & Randy & Timothy \\
\hline Benjamin & Dennis & James & Linda & Raymond & Tina \\
\hline Betsy & Derek & Jamie & Lisa & Rebecca & Todd \\
\hline Bill & Diane & Jane & Lori & Reginald & Tonya \\
\hline Bob & Dionne & Jason & Luis & Richard & Tracy \\
\hline Bradley & Donald & Jeffrey & Marcus & Robert & Travis \\
\hline Brandon & Donna & Jemima & Maria & Robin & Troy \\
\hline Brandy & Douglas & Jennifer & Mark & Rodney & Veronica \\
\hline Brenda & Edward & Jeremy & Martha & Ronald & Victor \\
\hline Brian & Edwin & Jerry & Mary & Ruairidh & Vivien \\
\hline Bridget & Elizabeth & Jesse & Matilda & Russell & Wanda \\
\hline Bruce & Emelda & Jessica & Matthew & Ryan & Wendel \\
\hline Calum & Emily & Jill & Maurice & Samuel & Wendy \\
\hline Camila & Eric & Joel & Melanie & Sandra & Wilbur \\
\hline Carlos & Erica & John & Melissa & Sarah & William \\
\hline Carrie & Erin & Jonathan & Michael & Scott & Xavier \\
\hline Catherine & Fiona & Jose & Michelle & Sean & Yann \\
\hline
\end{tabular}




\section{Figure Legends}

Figure 1. Topographic distribution of recollection and familiarity. Each cartoon shows the distribution of the difference between correctly recognised old items and correctly rejected new items. The front of the head is at the top of each map, and the left hemisphere is on the left-hand side. Each dot represents a recording electrode. The scale bars indicate the range of activity, plotted separately for each condition. The distribution of the old/new effect has a clear frontal focus for the 'name' and 'other specifics' retrieval conditions associated with recollection, but a posterior focus for the "no specifics' condition associated with familiarity.

Figure 2. Dissociation between recollection-related and late right frontal old/new effects. Representative ERPs from anterior sites (top half of the Figure); on the left-hand side, waveforms at FC2 are graded from roughly $400-800 \mathrm{~ms}$, with a significant difference between the two recollection conditions. On the right-hand side, the waveforms for the two recollection conditions are indistinguishable from one another until the end of the epoch. This dissociation between these two frontal effects demonstrates that the activity associated with recollection from $400-600 \mathrm{~ms}$ is modulated by different variables from the late right frontal old/new effect. At the bottom of the Figure, topographic maps showing the distribution of the name old/new effects across $5200 \mathrm{~ms}$ time windows. The data shown are derived from subtracting the amplitude of correct rejections from the amplitude of the name waveform. As can be seen, the effect is maximal at frontal superior sites during the first two time windows, while the effect is maximal at right lateral sites from $800 \mathrm{~ms}$ onwards. Topographic dissociations between the distributions of 
the recollection-related activity from $400-600 \mathrm{~ms}$ and the activity later in the epoch demonstrate that different cognitive operations underlie the two effects. 
Supplementary Table 1: Results of ANOVA for each old/new effect

\section{NAME v. CORRECT REJECTION}

Old/New

F $\quad \mathrm{F}(1,14)=30.4 ; \mathrm{p}<0.001$

FC $\quad \mathrm{F}(1,14)=46.1 ; \mathrm{p}<0.001$

C $\quad \mathrm{F}(1,14)=59.6 ; \mathrm{p}<0.001$

CP $\quad \mathrm{F}(1,14)=73.8 ; \mathrm{p}<0.001$

P $\quad \mathrm{F}(1,14)=85.3 ; \mathrm{p}<0.001$
Old/New * Hemisphere

$\mathrm{F}(1,14)=4.6 ; \mathrm{p}<0.05$

$\mathrm{n} / \mathrm{s}$

$\mathrm{n} / \mathrm{s}$

$\mathrm{n} / \mathrm{s}$

$\mathrm{n} / \mathrm{s}$
Old/New * Site

$\mathrm{F}(1.1,15.4)=10.8 ; \mathrm{p}<0.01$

$\mathrm{F}(1.4,19.0)=18.8 ; \mathrm{p}<0.001$

$\mathrm{F}(1.0,14.6)=12.2 ; \mathrm{p}<0.01$

$\mathrm{F}(1.1,14.9)=5.3 ; \mathrm{p}<0.05$

$\mathrm{n} / \mathrm{s}$
Old/New * Hemisphere * Site

$\mathrm{n} / \mathrm{s}$

$\mathrm{n} / \mathrm{s}$

$\mathrm{n} / \mathrm{s}$

$\mathrm{n} / \mathrm{s}$

$\mathrm{n} / \mathrm{s}$

\section{OTHER SPECIFICS v. CORRECT REJECTION}

\section{Old/New}

F

FC

C

CP

$\mathbf{P}$

$$
F(1,14)=14.6 ; p<0.01
$$

$\mathrm{F}(1,14)=16.2 ; \mathrm{p}<0.001$

$\mathrm{F}(1,14)=14.3 ; \mathrm{p}<0.01$

$\mathrm{F}(1,14)=16.7 ; \mathrm{p}<0.001$

$\mathrm{F}(1,14)=17.8 ; \mathrm{p}<0.001$
Old/New * Hemisphere

$\mathrm{n} / \mathrm{s}$

$\mathrm{n} / \mathrm{s}$

$\mathrm{n} / \mathrm{s}$

$\mathrm{n} / \mathrm{s}$

$\mathrm{n} / \mathrm{s}$
Old $/$ New * Site

$\mathrm{n} / \mathrm{s}$

$\mathrm{F}(1.2,17.4)=5.1 ; \mathrm{p}<0.01$

$\mathrm{n} / \mathrm{s}$

$\mathrm{n} / \mathrm{s}$

$\mathrm{n} / \mathrm{s}$
Old/New * Hemisphere * Site

$$
\mathrm{n} / \mathrm{s}
$$

$\mathrm{n} / \mathrm{s}$

$\mathrm{n} / \mathrm{s}$

$\mathrm{n} / \mathrm{s}$

$\mathrm{n} / \mathrm{s}$

\section{NO SPECIFICS v. CORRECT REJECTION}

\section{Old/New}

F

FC

C

CP

$\mathbf{P}$
Old/New * Hemisphere

$\mathrm{n} / \mathrm{s}$

$\mathrm{F}(1,14)=5.0 ; \mathrm{p}<0.05$

$\mathrm{F}(1,14)=5.5 ; \mathrm{p}<0.05$

$\mathrm{n} / \mathrm{s}$

$\mathrm{n} / \mathrm{s}$
Old/New * Site

$\mathrm{n} / \mathrm{s}$

$\mathrm{n} / \mathrm{s}$

$\mathrm{n} / \mathrm{s}$

$\mathrm{n} / \mathrm{s}$

$\mathrm{n} / \mathrm{s}$
Old/New * Hemisphere * Site

$\mathrm{n} / \mathrm{s}$

$\mathrm{n} / \mathrm{s}$

$\mathrm{F}(1.4,19.6)=4.9 ; \mathrm{p}<0.05$

$\mathrm{n} / \mathrm{s}$

$\mathrm{n} / \mathrm{s}$

$\mathrm{F}=$ frontal; $\mathrm{FC}=$ fronto-central $\mathrm{C}=$ central $; \mathrm{CP}=$ centro-parietal; $\mathrm{P}=$ parietal 
Supplementary Figure 1

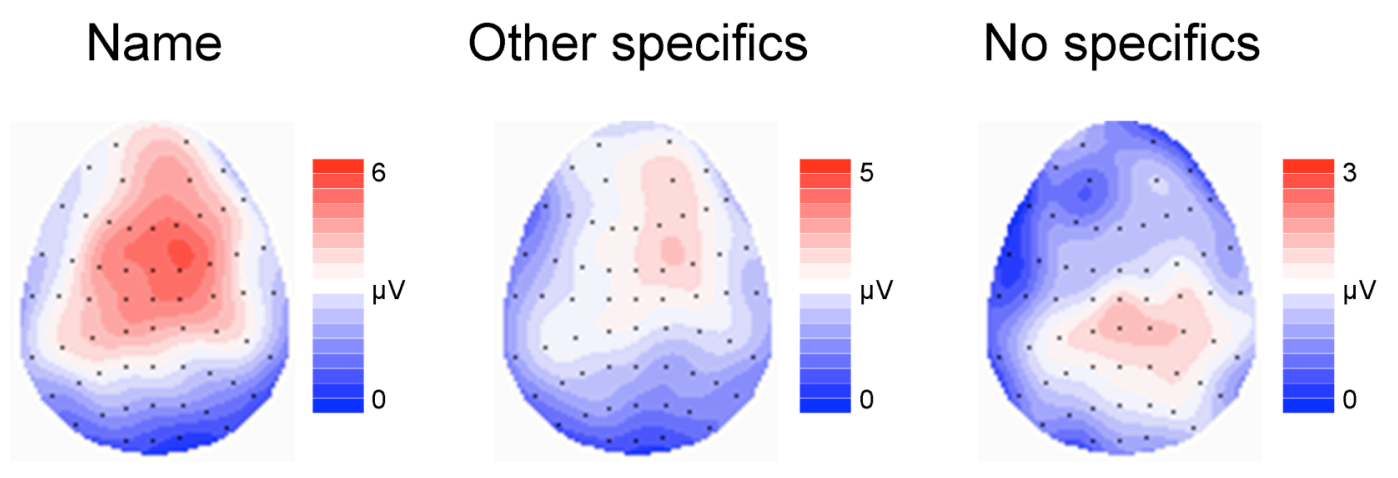


Supplementary Figure 2
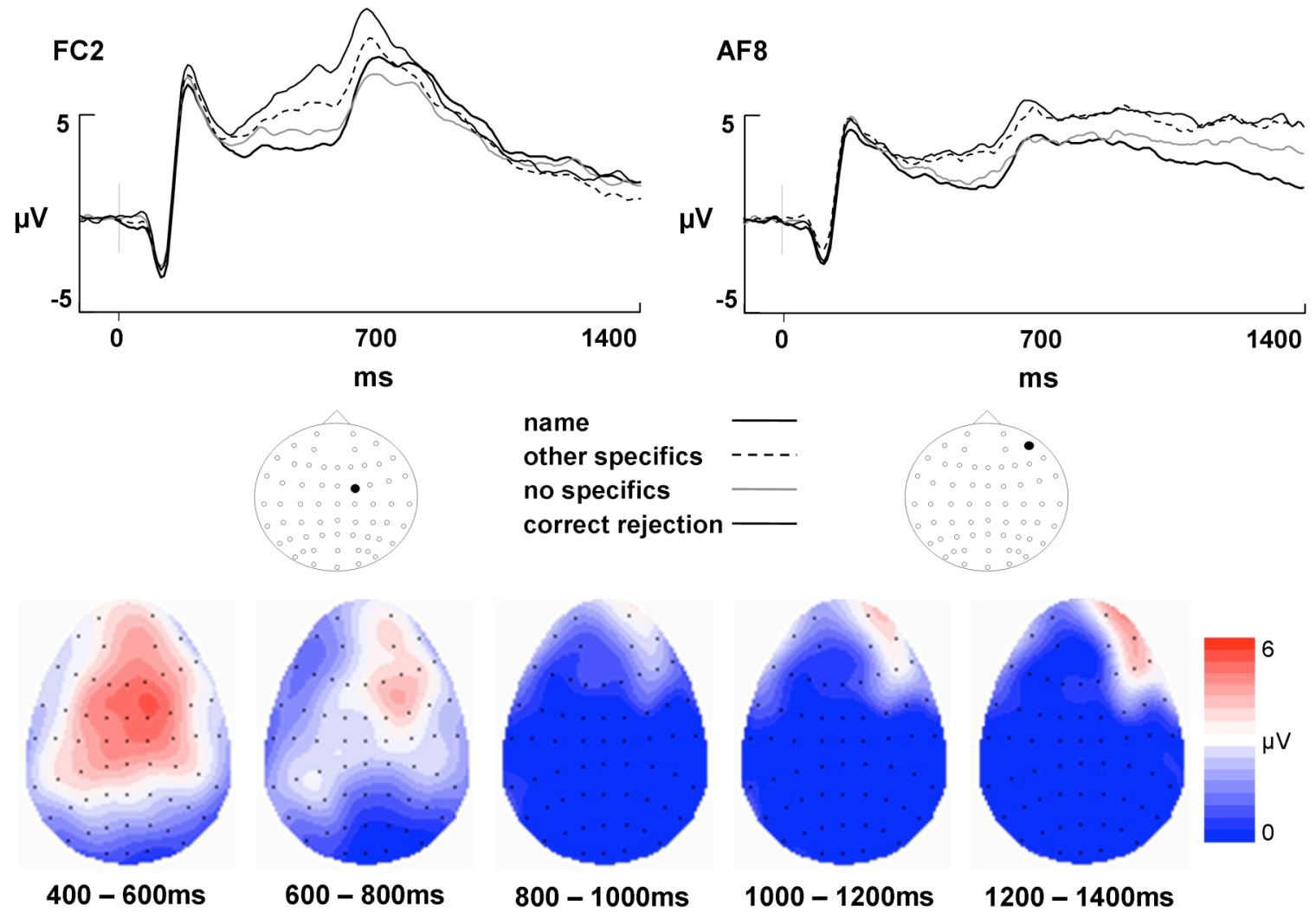